\title{
Nathan Jones
}

\section{THE TESTIMONY OF STRUCTURE: CODECS AND CONTEMPORARY POETRY}

APRJA Volume 5, Issue 1, 2016

ISSN 2245-7755

CC license: 'Attribution-NonCommercial-ShareAlike'. 
Many contemporary theorists have observed the increasing directness of the relationship of language to economics through technology. Coming from the Marxist tradition of the Italian autonomist movement, both Franco Berardi's The Uprising: Poetry and Finance (from 2012), and Paolo Virno's A Grammar of the Multitude (from 2003) contend that the special circumstances of post-Fordist industry - an industry based on cognitive and linguistic labour - places a great deal of focus on the cultural production of language. Thus, Virno describes culture itself as the new "industry of the means of production" (Virno 61) indicating that cultural explorations of communication complement or supersede technical industries making material machines and tools. Under the regime of semiocapitalism then, language artefacts acquire ontological status on a par with more explicitly technological devices. This entwinement of language as and with technology is most evident in the form of code, wherein machinic innovations themselves take the form of language, as software. But the narrow field of software production is clearly not the most profitable means by which finance can be drawn from what is linguistic - rather, social media corporations have found new ways of mining, quantifying and selling the testimony as the performance and recording of subjective experience. This article pursues the moment of the testimony in the context of this technologisation of language, and asks how contemporary literature might withdraw its innovations from the role they play in "industry of the means of production" through intimate sharing.

We can observe the pressures of this shifting status of literary innovation in popular contemporary genres such as Autofiction and Alt Lit, both of which explore deep and/ or continual sharing as literary forms: a tendency which has implications in the personal lives of those who share, or are shared. The excessive autobiographical content in Karl Knausgaard's trilogy My Struggle (from 2013), or Tao Lin's novel Taipei (from 2013) for example, have resulted in accusations of abuse from people connected to the authors - their wives and girlfriends in particular. In a radio interview, Knausgaard has described as a "Faustian pact" the sacrifice of family relationships he made in achieving success with his book (Gundersen).

This burden of oversharing in which the potential of language goes to work within the subject as energetic mining activity, is exemplary of what Berardi identifies as the emotional and psychic strains of the flow connecting cognition and finance:

\section{The field of desire has been invaded} by anxiogenous flows: the acceleration of the infosphere has expanded expectations, semiotic stimulation, and nervous excitement up to the point of collapse. (Berardi 109)

That is, it becomes ever more implausible to think of a limit to the reach, scale and speed of the language-technology apparatus, and thus we are held at this point of anxious collapse, needing to say, type, read, send, record in order to exist at all - while needing equally to fall back into one's self in order to innovate and devise new aspects about our selves which might be valuably shared. The objectifying of language in terms of financial value - of which the quantification through textual analysis is one part of its inclusion in "the objective order of things in themselves" (Fuller) - produces an uncanny departure from the enunciation's traditional value as a more or less vanishing mediator between subjects and objects. The work of contemporary poets, in this context, is to propose a form of address which problematizes the objectification of language as distinct from its subject, and allows its conditions to speak 
through it: to speak from the conditions of the technological, the impossibility of speaking about technological conditions.

\section{Posthuman subject}

But what differentiates the objectified language of the technological from the language which has come before? After Donna Haraway, Katherine Hayles designates a posthuman realm in which bodily language is submitted to sampling and quantification - codification - in return for its entry into the data stream. The basis of the relation between meaning and word in this language, Hayles argues, is radically shifted from that of the "Lacanian 'floating signifier"' in which words are located in relation to meanings in context, to the "flickering signifier", where meaning is only ever a degree of probability (Hayles 29). That is, language moves from affirming presence and absence of meaning in context, to existing as a flickering play of pattern and randomness, thus having to do with the numerical statistical array. Enunciation under these conditions becomes a matter of probability, distinguished from the presence of the enunciating subject. Berardi suggests that this shift from the structure of possibility in presence/absence to that of probability in pattern/randomness was performed firstly in symbolist poetry (18). He connects the symbolist project's separation of signifier from signified explicitly to the way that markets moved from physical to semiotic labour:

[S]ymbolist poets enhanced the connotation potency of language to the point of explosion and hyperinclusion.

[...] This magic of post-referential language anticipated the general process of dereferentialization that occurred when the economy became a semio-economy. (Berardi 18)

Conversely, what Berardi calls for in poetry implying a new, or a return to, non-utilizable cultural language - is an enunciation of the sensuous qualities of language, which he designates variously as its "the voice" or "excess". This return of poetry as the excess of language refers to the enunciation of the explicit and irrevocable presence of the subject; by stammering, marking or otherwise refusing the purity of the statement and therefore preventing its quanticized inculcation into the technological. The potential of excess in this instance is to prevent the collapse of the act of enunciation into the objective completion of the statement.

\section{Incoherence}

In The Interface Effect (from 2015), Alexander Galloway proposes four regimes for art, based on their political and aesthetic incoherence or coherence. Ideology for example, is proposed to be politically coherent - it is aligned to a dogma - and aesthetically coherent in order to make clear sense. Galloway finishes by proposing that it is to the "dirty regime" of truth, where works intersect political incoherence and aesthetic incoherence that we must look for works that are capable of speaking in non-generic ways through technology. This, he says is an analogue of Giorgio Agamben's theory of 'the whatever':

The whatever finds its power in incontinence and transformation, not unification or repetition. Likewise the whatever is politically incoherent because it tends to erode existing territories and institutional routines [...] No centre exists toward which it might gravitate. (142) 
Artworks of the regime of truth, or the whatever, it is suggested, offer a radical subjectivity for the poem in which the increasingly coercive and invisible process of structuring by interfaces are made available for critique, as essential parts of the unique qualities of the speaking/writing subject: "effacing representational aesthetics and representational politics alike, in favour of direct immanence" (142). The politically unaligned and aesthetically inconsistent work, almost by definition, is one which comes into contact with limits - the ends which would match up and hold the work together in itself (aesthetic coherence) and align it with social frameworks outside of itself (political coherence), are left ragged, and the work doesn't collapse into the generic: "neither a universal nor an individual included in a series, but rather 'singularity insofar as it is whatever singularity'" (Agamben, The Coming Community 1).

Singularity is essential to thinking how a work operates, or fails to, in the 'infosphere', wherein everything is accorded value on the basis of transient status in a database of generic categories. So what are the qualities of a contemporary poetry of the whatever, and how do they perform the "voice of language" as excess? As critiques of both Galloway and Berardi have observed (Fest, lliadis), neither are keen to build on their manifestos with reference to examples in contemporary artistic practice. But what is clear from both authors, is that they draw on the work of Agamben to identify the incursions of such limits specifically in language. So, it is necessary to ask, what is Agamben's understanding of the excess of language? And how does this play against the new posthuman and techno-linguistic context which Berardi and Galloway identify as the realm for a contemporary poetics?

\section{The contemporary}

I would like to start to answer these questions with perhaps the least conspicuous term they suggest - the contemporary. Agamben has a specific understanding of the contemporary, as someone who is able to view 'the darkness' of his or her time (Agamben, What is an Apparatus?). He uses the metaphor of the darkness in the night sky, which he says is not the darkness of absence, but rather of those stars which move away from us so fast their light, while approaching, never reaches us - they withdraw: "To perceive, in the darkness of the present, this light that strives to reach us but cannot - this is what it means to be contemporary." (50)

In Remnants of Auschwitz, Agamben again draws on this same cosmological metaphor to affirm darkness itself as trope of the language of the impossible - a language which contains that which is in excess of itself as a remnant.

This is language of the "dark shadows" that Levi heard growing in Celan's poetry, like a "background noise"; this is Hurbinek's non-language (mass-klo, matisklo) that has no place in the libraries of what has been said or in the archive of statements. Just as in the starry sky that we see at night, the stars shine surrounded by a total darkness that, according to cosmologists, is nothing other than the testimony of a time in which the stars did not yet shine, so the speech of the witness bears witness to a time in which human beings did not yet speak; and so the testimony of human beings attests to a time in which they were not yet human. (Remnants of Auschwitz 162) 
The darkness of our time in contemporary poetry refers to that which is withdrawn from us about the poem's techné, which operates prior to, but normally in excess of, the poem itself. A broken language in which the unsayable is present as remnant is for Agamben, as with Heidegger, how the contemporary commutates what is withdrawn from language. The possibility of poetry as the word of the subject whose testimony is always about to be objectified and categorised into the technical apparatus of the database - and therefore impossible as anything other - is to bring the darkness which exceeds language into the poem, putting it into a position where it contains that which would normally necessarily withdraw from it in order for it to function in the "archive of statements" (Agamben, Remnants of Auschwitz 162). It is the voice of language which exceeds its collapse into a generic form.

\section{The withdrawn}

Drawing on the foundational work of Heidegger, in The Open: Human as Animal, Agamben (71-75) affirms a distinction between the human open-ness and animal self-withdrawal of which he says the humanas-animal is composed. I posit a similar move in considering the boundary of human open-ness and technological self-withdrawal which makes up the posthuman writing subject - that is, the subject who operates within, and is operated on by, technological language.

For Heidegger, a tool necessarily withdraws into invisibility while we express our own being through it - using it to our ends. Galloway similarly has written of the invisibility of media and interfaces thus: the better they work, the more invisible they become (11). To look at the other side of the coin, our experience of devices is precisely and uniquely the experience of their faultiness. This, what Heidegger called un-readinessto-hand (Heidegger 204-207), when a tool becomes unavailable, broken or unwieldy, is a moment in which the tool discloses itself in relation to someone who would use it. Importantly, this disclosure is specifically related to an aspect, that is, the nature of its unsuitability in-relation-to - a specific subjective quality only apparent in relation to a proposed use.

Like the animal in Agamben's account, software's interaction with the world is poor, having to do with the activity of enframing, or structuring, rather than the human's active concern with the world. The split in the writing subject is between the poor structuring activity of technological language, and the involved concern which drives the enunciation. But this split has become infinitely complex in the contemporary conditions of technological language, whose role as a tool for communication has been morphed into that of the agent towards a particular form of disclosure. As I sought to show at the beginning of this paper, the enunciation is always to an extent driven by the current technological bias towards disclosure, and language itself is not a pure means but has deep connections to what wills itself to be said. The contemporary poet's untimeliness by definition, must write from within this paradox at work within the poem as the manifestation and refusal, of a desire to share. In writing at limits, what the contemporary poet brings back from withdrawal is their own withdrawn technological aspect: the excess and lack which accompany and allow for the poem to testify to technology as part of the conditions for saying. 


\section{Codec and glitch}

But what is the unhuman element of the posthuman subject against which the testimony becomes both an excess and a lack? And how might a poet bring back from withdrawal those elements which structure it, in order to include them as part of their subjective encounter? Embracing the apparent anachronism, I would like to use the framework suggested by the relation of media to digital codecs, and the ways in which codecs have been retrieved and performed in glitch art.

A codec (compression-decompression/ coding-decoding) is a process which allows for the most salient features of new media - namely the sampling and quantifying by which it objectifies media as a statistical array. The low-order language in which a digital media item is stored is called the data, and that protocol which allows for it to be shown the interface. Codecs (such as those having the file extension .jpg, .tiff, .raw) store visual information as data, in a string of alphanumeric figures. Before being run by the codec interface, the data itself does not conventionally exist on the plane of the human subject - as visible - and after, both the interface and data are withdrawn from what we see, they are the darkness against which the image appears.

Two aspects that are important to note about this relation: 1 ) both the data and the interface used in combination to make the image immanent, occlude themselves in revealing the image - they are the excess which is in the saying of the image; 2) The data of the storage format stakes no claim to being the originary, or 'essence' of the image, being only precisely the a-priori, not containing either the exhaustive information with which the image can reveal itself (for it requires the interface for that), nor to contain everything that will be shown (for any viable interface could show a singularly different version of it), nor having any privileged relation to the real (being structured like a language).

The salient innovations of glitch art brought the data and the interface in a codec into immanence as part of the artefact. Artists such as Rosa Menkman, in Vernacular of File Formats (in 2008) and Nick Britz in Glitch Codec Tutorial (from 2011) using pedagogical methods and series' of images and films, forced the codec to disclose itself, by editing the source code of data or interface in order to produce situations wherein they fail to articulate, corrupt, or stammer their data. Often in glitch art, a series is used to show, via the aesthetic differences of each image in the series, the biases and aesthetics of specific codecs, and perform the codec process itself as the mediation of what is the apparently unmediated. The resulting images then literally exceed their data, being added-to by patterns, colourings, warps from the interface, while also becoming diminished, half-withdrawing from view in favour of the 'darkness' of their structure. The image or video itself becomes both excess and lack - paradoxically unrealised as that which it should show, while showing more than it should. The glitch in the work of these artists was an untimely gesture, operating in such a way that stammered and problematized the apparent fluency of digital media by refusing to let the image become itself and therefore be inculcated as an object in the network of objects.[1] I will now turn to a reading of a contemporary poetry book, Mean Free Path, by Ben Lerner, to show how it exhibits glitchlike tendencies, of series and the breakdown of structuring aspects, to perform its own testimony to its technological conditions. 


\section{Mean Free Path}

Mean Free Path (from 2010) is a book, within which there is a poem also called "Mean Free Path" split across two sections by a poem called "The Doppler Elegies", and prefaced by a "Dedication". The poem "Mean Free Path" is composed of two sets of thirty-six stanzas of nine lines each, two of which appear on each page. In a form which mimics digital media's "modular" or fractal quality (Manovich), the stanzas in series do not develop on each other in a linear way, but rather pertain to their own aphoristic completion - each containing the thematic and affective qualities of the poem as a whole. This aphoristic, elliptical quality is in evidence down to the units of the phrase also, as units which are revisited in transformational arrangements at different moments in different stanzas - variously operating as an element of noise or signal at different moments throughout. Although, and because, all of what the poem testifies to is present as potential in each moment of its enunciation, any one quotation - or sampling - necessarily performs only a partial disclosure. The units by which it is sampled blur at their edges, the speaking they do uttered from the lacunae between them, and that which appears integral in one stanza quickly being transformed as excess in another. This is the quality of repetition - or rather the problematizing of repetition. By refusing to dissolve each enunciation into what has been said and which would then be repeatable, the poem "Mean Free Path" wilfully enters its testimony through the disorganizing principles of digital media's emphasis on the statistical array as continually modifying and refreshing the quality of meaning. To return to the figure of the codec, the drama that plays out across the book is experienced as though each stanza is a consistent data source as potential, realised by an unstable interface, the data sputtering and drawing striations or remnants indistinguishable from the meaning of the poem on the surface of the text.

The poem as constituted of re-coded/ de-coded series can be read as a continual return to the possibility of the poem begun anew in each moment, producing incoherence across the whole, which nonetheless continually appears to bloom into disclosure. For example, the sentiment of a kind of proxy subjectivity in the second stanza "I'm writing this one as a woman / Comfortable with failure" (9) is developed in the sixth as "Reference is a woman / Comfortable with failure" (11) then re-versioned in the twelfth as "I'm writing this one / With my nondominant hand in the crawl space / Under the war" (14) and again in the next stanza as "I'm writing this one / As a woman comfortable with leading / A prisoner on a leash" (15). The cumulative effect of this assertion of new proxy voices for the poem - itself a glitch in the otherwise consistent authorial voice of Lerner himself - each neither incompatible nor reinforcing each other turns the continual desire for re-production of the subject in the data-stream, back on itself as a principle which warps and obscures the text.

One reading of the poem "Mean Free Path" which is useful to examine in relation to the relation of obscuring-revealing indicated here, is that it is a love poem for Lerner's wife: "a little book for Ari / Built to sway" (12). The technological occasion of Lerner's articulation of this subjective experience is specifically one in which the irrevocability of the subject-object relation required for love is subordinated to an objective patterning of elements. The technological doesn't allow for the irrevocable presence of meaningfulness in romantic love, but rather insists that everything must be the result of a greater or lesser 
degree of objectively quantifiable patterning. Lerner's response is to introduce an excess of meaning in which love operates among and between, refusing the foreclosure of any singular phrase, and therefore maintaining the subject's relation, in enunciating, to the enunciation itself - stammering at the limits of having said, by always falling short of being able to say:

I know it's full of flowers, music, stars, but

But the pressures under which it fails

How it falls apart if read aloud, or falls

What we might call its physics

Together like applause, a false totality

Scales (56)

In this penultimate stanza, we see the interruptive quality of different strands or layers of the poem being utilised as a kind of 'false totality' in which it is their resonance among each other, which produce the excessive, unfinishable quality. The writing of excess and lack in "Mean Free Path" as a poem does not explode into (and therefore gesture at) limitlessness, breaking down boundaries of decency, rapidity, scale for example, but rather stammers at the limit of what has and hasn't been said - communicating the condition of its own limits as a collapse, or fall, into its unique conditions, "what we might call its physics."

In this physics of sense, each phrase appears to us as a singular 'bit', reappearing in any number of different contexts throughout the poem. The systematic incoherence generated by these contexts crafts in the work a distinctive liquidity or vapourousness which is at odds with previous poetics which have foregrounded the 'fragmentary'. Rather than a logic of parataxis in which units are distinct, fragmentary and comparable, we have a logic of hypostasis, where breakages become the site for the production of meaning-as-pattern, which is the distinguishing quality of the digital 'stream':

\section{I'm not above being understood, provided}

The periodic motion takes the form of

Work is done on the surface to disturb

Traveling waves. (48)

This sense of leaking or liquidity among the stanza and across stanzas - a trope of the digital - is twisted by Lerner, to communicate a potential which exceeds the horizon of the poem's interaction with codification per-se. This is achieved through the explicit surrender of syntax to the logic of sampling its broken language. All the way up, zooming out of the structure of the poem, we anticipate a coherent poetic image or a full sentence to emerge as one-in-a-series, but this closure is continually offset by the peculiar relational singularity of its elements:

\section{I planned a work which could describe itself \\ Into existence, then back out again Until description yielded to experience Yielded an experience of structure Collapsing under its own weight like Citable in moments: parting}

The system of relations between what is sayable and unsayable in each stanza then, is also continually deferred. The irreconcilable is the singularity operating in excess of what can be said, the singularity of the posthuman subject who testifies to their own untestifiable condition:

There must be an easier way to do this I mean without writing, without echoes Arising from focusing surfaces, which should

Should have been broken by struc tures (40) 
[...]

But not how you mean that, not without Arising from focusing surfaces charged

Changed in the familiar ways. Little contrasts

With the task of total re-description To begin the forgetting, a gentle rippling (54)

\section{The shadow of sampling}

What I call the glitch poetic in "Mean Free Path" is the writing of excess. This is not human attainment surpassing the speed and efficiency of digital media, nor is it a human testimony explicitly falling short of the demands made of it by the technological. It is rather the moment produced when the sampling, quantifying activity integral to infosphere does not exhaust that which it structures, but rather exhibits the shadows of its failure to do so.

Sampling and quantification as technological structuring of language inaugurate a new poetic form, and by reading poems which work in excess of this form, it don't mean that the form breaks, but rather the sayable in them is tangibly corrupted by its emergence through them. The glitch poetic is a particular performance of the voice of a new kind of language, grounding and recontextualising itself in a shifting linguistic environment. As Berardi calls for, the glitch poetic signifies for the posthuman body, a "reemergence of the deictic function (from deixis, self-indication) of enunciation [...] sensuously giving birth to meaning." (20)

\section{Notes}

[1] The glitch has notoriously been inculcated thoroughly into the financial through commercialization and commodification of its visual and sonic tropes (Britz, in Urquart), leaving many of its central practitioners to abandon the term - or produce more nuanced and multi-platform versions of its core techniques. The glitch poetic would be part of this effort to reclaim the activist glitch tradition from the saturation of its tropes in visual and sonic mediums.

\section{Works cited}

Agamben, Giorgio. Remnants of Auschwitz: The Witness and the Archive. New York: Zone Books, 1999. Print.

Agamben, Giorgio. The Open: Man and Animal. 1st ed. Stanford, California: Stanford University Press, 2003. Print.

Agamben, Giorgio. What Is an Apparatus? And Other Essays. Stanford, California: Stanford University Press, 2009. Print.

Agamben, Giorgio. The Coming Community. Minneapolis: Univeristy of Minnesota Press, 2006. Print.

Berardi, Franco Bifo. The Uprising: On Poetry and Finance. Los Angeles: Semiotext(e), 2012.

Britz, Nick. "Glitch Codec Tutorial [glitch Art Demo] Full Tutorial." Vimeo, 2011. Web <https://vimeo.com/23653867>. 
Fest, Bradley J. "Poetics of Control."

Boundary 2 July 15, 2015. Web

$<$ http://boundary2.org/2015/07/15/

poetics-of-control/>.

Galloway, Alexander R. The Interface Effect. Oxford: John Wiley \& Sons, 2012. Print.

Gundersen, Trygve Riiser. "Knausgård burde være glad." [Knausgård should be happy] Dagbladet, Oct. 3, 2010. Web <http://www.dagbladet.no/2010/10/03/kultur/ litteratur/bok/13675318/>.

Hayles, Katherine N. How We Became Posthuman. Chicago: University of Chicago Press, 2008. Print

lliadis, Andrew. "Franco 'Bifo' Berardi's the Uprising - Book Review." Marx \& Philosophy Review of Books. 30 July 2013. Web <http://marxandphilosophy.org.uk/ reviewofbooks/reviews/2013/799>

Knausgaard, Karl Ove. A Death in the Family: My Struggle. New York: Vintage,. 2013. Print.

Lerner, Ben. Mean Free Path. Port Townsend, Washington: Copper Canyon Press, 2010. Print.

Lin, Tao. Taipei. Edinburgh: Canongate Books, 2013. Print.

Manovich, Lev. The Language of New Media. $8^{\text {th }}$ ed. Cambridge, MA: MIT Press, 2002. Print.

Menkman, Rosa. "Vernacular of File Formats." Aug. 2008. Web. <http:// rosa-menkman.blogspot.co.uk/2010/08/ vernacular-of-file-formats-2-workshop.html>.
Urquhart, Robert. "The Distorted Truth in Glitch.” 2012. Web <http://roberturquhart. blogspot.co.uk/2012/02/distorted-truth-ofglitch.html>.

Virno, Paolo. A Grammar of the Multitude. 1st ed. Cambridge, MA: Semiotext(e), 2003. Print. 